such scientifically unsupported optimism into the domain of preventive medicine 'cannot be justified'.

The fifth chapter, on alternative medicines, pours scorn on their pseudoscientific claims. It attributes any efficacy which they may have to the placebo effect, which, once again, they appear to denigrate as being inconsistent with honesty, which they rate highly, and with truth based on scientific evaluation.

Their sixth chapter and the concluding Envoi return to the issue of the morality of modern medicine. Insofar as it has had a successful impact, they attribute it to its pursuit of truth, a pursuit which they see as embodied in the scepticism of basic scientific methods, a scepticism which they regard as virtually absent from presentday medical education.

Many of the ends of their controversial statements are by no means tied up and convincing. For this reason, perhaps, it could usefully become a text to encourage the medical profession's neophytes to think more deeply about the moral and social consequences of the trade they are learning. It is to be hoped, however, that the arguments they use so appealingly will not be accepted without themselves being subjected to the scepticism and criticism of received wisdom which they advocate.

MARGOT JEFFERYS Emeritus Professor of Medical Sociology, University of London

\section{Medical Ethics and the Value of Life}

Edited by Peter Byrne, 162 pages, Chichester, £13.50, John Wiley and Son, 1990
This latest volume in the excellent series edited by Peter Byrne will prove of most use and interest to those engaged in the teaching of medical ethics. The style and academic level of the articles included ranges from the chatty and anecdotal to the philosophically demanding, thus allowing the teacher to extract material appropriate to a variety of audiences.

The first topic raised in the volume is that of euthanasia. $\mathrm{H} \mathrm{J} \mathrm{J} \mathrm{Leenen} \mathrm{offers}$ an informative account of the current Dutch position on euthanasia and the political and legal debates surrounding the issue in that country. The article is less useful as an account of the ethical issues involved, as the author, an obvious proponent of euthanasia, tends to dismiss his opponents' arguments rather too easily. Peter Byrne's article however, which discusses the recent BMA report on euthanasia, is an excellent introduction to the issues involved and the philosophical arguments employed in this area. I expect to find this article particularly helpful in a teaching context; similarly Basil Mitchell's article on the value of life, which is a clear and concise account of the opposing views held on the subject. Although the author fails to reach any great conclusions himself, there is no evidence of the 'dreary confusion and obtuseness of mind' he apologises for at the beginning of the paper.

In his preface the Editor warns that Sophie Botros's article, 'Abortion, Embryo Research and Fetal Transplantation' will prove challenging, and I suspect many readers will consider this an understatement. This is a difficult paper, deserving careful attention, which it may not receive in this context, and I question the decision to include it.

I would also wish to make a more general criticism concerning the selection of articles. The Editor explains that the volume 'covers a wide range of issues while focusing on a series of related themes', with some issues being carried over from earlier volumes of the series. The inclusion of two papers on the teaching of medical ethics results from the Editor's probably correct belief that the BMA report on euthanasia 'fuels doubts about whether philosophers and reflective medical practitioners can communicate successfully'. Roger Higgs raises the question of whether medical ethics can be taught, a question that will interest both ethicists and medical practitioners. Raanan Gillon offers his impressions on the teaching of medical ethics in the United States. Gillon's article is interesting, especially to those attempting to teach the subject in this country, but I felt the pages could have been better used to discuss issues more obviously related to the central theme of the volume. I had similar doubts concerning the Bishop of Oxford's paper which called for tolerance to be shown towards people with AIDS. Although I welcome such a message from a leading churchman, I felt his paper added little to the coherence of the volume as a whole.

Given the enormity of the ethical issues surrounding euthanasia, and the broader issue of the value of life I would have preferred to see more space being devoted to these subjects. Having said this, I enjoyed the two remaining articles, Albert Weale's discussion of resource allocation within a democratic system, and John Mahoney's exploration of whether or not it is right to allow parents to select the sex of their children.

CALLIOPE FARSIDES Department of Philosophy, University of Keele 